\title{
Vulnerabilidade e Adaptação às Mudanças Climáticas: Análise de Agricultores da Bacia Hidrográfica do Rio das Contas
}

\author{
Victor Gaston Nogueira ${ }^{1}$ (D) | Elizângela Aparecida dos Santos ${ }^{2}$ (iD | Dênis Antônio da \\ Cunha ${ }^{3}$ \\ ${ }^{1}$ Programa de Pós Graduação em Economia Aplicada, Departamento de Economia Rural, Universidade Federal de \\ Viçosa. E-mail: victorvgn@gmail.com \\ 2 Programa de Pós Graduação em Economia Aplicada, Departamento de Economia Rural, Universidade Federal de \\ Viçosa. E-mail: elizangela.santos@ufv.br \\ ${ }^{3}$ Programa de Pós Graduação em Economia Aplicada, Departamento de Economia Rural, Universidade Federal de \\ Viçosa. E-mail: denis.cunha@ufv.br
}

\begin{abstract}
RESUMO
O objetivo deste artigo foi compreender a vulnerabilidade e os principais condicionantes do processo de adaptação de agricultores da bacia hidrográfica do Rio das Contas, localizada na região Nordeste do Brasil. A vulnerabilidade foi analisada a partir de índices representativos de suas três dimensões: sensibilidade, exposição e capacidade adaptativa. Para analisar a adoção de estratégias de adaptação, utilizou-se o modelo Probit. Os principais resultados permitiram concluir que a região estudada possui níveis altos de vulnerabilidade, sobretudo devido aos baixos valores de capacidade adaptativa. Os condicionantes da adaptação mais relevantes se relacionam ao grau de escolaridade e à formação agropecuária dos agricultores, bem como à participação em projetos de irrigação, ao recebimento de assistência técnica, à localização geográfica e ao grau de exposição às mudanças climáticas. Nesse sentido, políticas públicas que visem ao combate à vulnerabilidade deveriam focar, sobretudo, no fortalecimento das condições socioeconômicas regionais.
\end{abstract}

\section{PALAVRAS-CHAVE}

Mudanças climáticas, Vulnerabilidade, Adaptação, Agricultura

\section{Vulnerability and Adaptation to Climate Change: Analysis of Farmers in the Rio das Contas Hydrographic Basin}

\begin{abstract}
This paper aims to understand the vulnerability and the adaptation process of farmers in the Rio das Contas basin, located in the Brazilian Northeast region. The vulnerability was analyzed using indexes representative of its three dimensions: sensitivity, exposure, and adaptive capacity. To analyze the adoption of adaptation strategies, the Probit model was used. The main results indicated that the region has high levels of vulnerability, mainly due to the low values of adaptive capacity. The most relevant conditions for adaptation are related to the education level and the farmers ${ }^{-}$agricultural training, as well as participation in irrigation projects, receiving technical assistance, geographic location, and degree of exposure to climate change. In this sense, public policies for the reduction of vulnerability should focus on strengthening regional socioeconomic conditions.
\end{abstract}

\section{KEYWORDS}

Climate change, Vulnerability, Adaptation, Agriculture

\section{CLASSIFICAÇÃO JEL}

Q12, Q54 


\section{Introdução}

As mudanças climáticas estão entre os principais desafios enfrentados pelos países no século XXI (Ripple et al., 2017). O fenômeno pode impactar a composição, a resiliência ou a produtividade de ecossistemas naturais e gerenciados, a operação de sistemas socioeconômicos ou a saúde humana e o bem-estar das populações. Um dos setores mais vulneráveis e que potencialmente sofrerá os maiores impactos negativos é a agricultura, sobretudo de países em desenvolvimento (Tol, 2018).

Os efeitos da perda de produtividade agrícola sobre o bem-estar humano dependerá em grande parte da capacidade de os agentes econômicos se adaptarem, ou seja, de se ajustarem às novas necessidades impostas pelos cenários climáticos futuros (Cunha et al., 2015; Haddad et al., 2013). Disponibilidade de informação, novas tecnologias, instituições eficientes, facilidade de acesso a mercados de bens, serviços e oportunidades de financiamento aumentam o sucesso dessa empreitada, mas são justamente nesses pontos que os países em desenvolvimento se encontram mais deficientes (Hertel e Lobell, 2014). Soma-se a isso o fato de que tais países têm sua economia com expressiva dependência da atividade agrícola e estão localizados em regiões onde as condições climáticas já se aproximam dos limites tolerados pelas plantas e pelos animais.

Todas essas questões possuem especial importância na região Nordeste do Brasil, para a qual são esperados cenários futuros de mudanças climáticas severas, com grandes aumentos da temperatura e da variabilidade da precipitação. Trata-se, portanto, de grande desafio, em especial para os pequenos agricultores, cujo potencial de lidar com os impactos adversos das alterações do clima é baixo (Lindoso et al., 2014). As mudanças climáticas esperadas podem ampliar ainda mais a vulnerabilidade desses agricultores que, historicamente, enfrentam intensas dificuldades em termos ambientais e sociais e, desse modo, ampliar as desigualdades regionais (Delazeri et al., 2018).

Nesse contexto, o objetivo do presente artigo foi analisar a vulnerabilidade e o investimento em estratégias de adaptação às mudanças climáticas de agricultores da Bacia Hidrográfica do Rio das Contas, na Bahia. Trata-se da maior bacia hidrográfica localizada no território baiano, em cuja área vive cerca de $15 \%$ da população do estado. A região tem sua economia bastante dependente das atividades agropecuárias e, desde a década de 1990, está passando por dificuldades em razão das constantes secas (Agência Nacional de Águas e Saneamento Básico - ANA). A pesquisa procurou oferecer um panorama local e, portanto, contribuir para a literatura sobre impactos regionais das mudanças climáticas na agricultura brasileira.

Considerando as expectativas do Painel Intergovernamental sobre Mudanças Climáticas (Intergovernmental Panel on Climate Change - IPCC) acerca do aumento dos níveis globais de exposição às mudanças climáticas, é vital mapear a vulnerabilidade regional com vistas a diminuir a sensibilidade e a aumentar a capacidade adaptativa 
dos agricultores. A adaptação, quando efetivamente desenvolvida, minimiza prejuízos e perdas resultantes de eventos climáticos extremos e das mudanças climáticas em geral, aumentando a resiliência dos sistemas. Dessa forma, o entendimento da vulnerabilidade e de como a adaptação é desencadeada é essencial para que se encorajem mais iniciativas por parte do Poder Público e dos agricultores.

Ao decidir por um estudo de caso, esta pesquisa levou em conta que, embora as mudanças climáticas constituam-se um fenômeno global, é localmente que os impactos são vivenciados e onde as estratégias para lidar com o fenômeno são efetivadas Nash et al. (2019). De acordo com Reyes-García et al. (2016), "povos locais estão sendo cada vez mais reconhecidos como aliados em potencial na busca de entender melhor as mudanças climáticas e seus impactos”. Esses autores também ressaltam que comunidades locais, em geral, desenvolvem complexos e intrincados sistemas de conhecimento sobre variabilidade e mudança do clima e seus efeitos sobre os sistemas físicos, biológicos e socioeconômicos.

É válido mencionar que a maioria dos estudos realizados no Brasil se concentra em análises de nível global ou nacional com relação a futuros impactos, desconsiderando a vulnerabilidade e a adaptação regional ou local. Mesmo sendo importante a formulação de estudos e políticas relacionados às mudanças climáticas de plano nacional ou internacional, muitos dos impactos na agricultura apresentam elevado grau de especificidades em relação às condições ambientais e sociais locais (Lee et al., 2014). Portanto, o presente estudo oferece um panorama local, de modo a esclarecer o porquê de alguns agricultores serem mais vulneráveis do que outros e que fatores fazem com que as estratégias de adaptação sejam distintas entre eles.

Dada a diversidade espacial dos impactos, as estratégias de adaptação com maior potencial de sucesso são as que levam em consideração as particularidades locais ou regionais. E a melhor compreensão das questões relacionadas à adaptação, ainda que não elimine as perdas, pode contribuir para tornar a renda dos agricultores mais estável, o que levaria à melhora de sua qualidade de vida. O sucesso dessas estratégias depende, em última instância, do mapeamento e da compreensão da vulnerabilidade local. Como os formuladores de políticas públicas são agentes que atuam no nível microrregional, podem escolher a melhor alocação dos recursos a partir do conhecimento local (Lee et al., 2014). Com a finalidade de fomentar o uso de estratégias e técnicas de adaptação mais efetivas, é necessário adequar o escopo das políticas públicas nacionais às peculiaridades locais.

Por fim, as questões enfocadas neste estudo estão em consonância com a agenda de desenvolvimento regional brasileiro dos próximos anos, como o Plano Regional de Desenvolvimento do Nordeste (PRDNE) proposto pela Superintendência do Desenvolvimento do Nordeste (SUDENE). Entre outras ações, o PRDNE visa mapear vulnerabilidades socioeconômicas e ambientais de modo a propor ações de convivência com as mudanças climáticas, aumento da resiliência local, da diversificação produtiva e da capacidade de adaptação de modo geral. Dessa forma, acredita-se que os resultados 
da pesquisa contribuirão para direcionar a tomada de decisão de agentes públicos e privados.

Além desta introdução, o presente artigo encontra-se dividido em mais cinco seções: descrição da área de estudo, revisão de literatura, metodologia (com descrição das etapas da pesquisa e fundamentos teóricos), descrição e análise dos resultados encontrados e, por fim, a seção de conclusões.

\section{2. Área de estudo}

Considerando-se que o território baiano é geograficamente vasto e que, em razão disso, apresenta características edafoclimáticas e realidades socioeconômicas diversas, a presente análise se desenvolveu a partir de uma perspectiva local, enfocando agricultores cujas propriedades estão localizadas na bacia hidrográfica do Rio das Contas, Bahia (Figura 1).

Figura 1. Localização da bacia hidrográfica do Rio das Contas em relação ao estado da Bahia, à região nordeste e ao Brasil

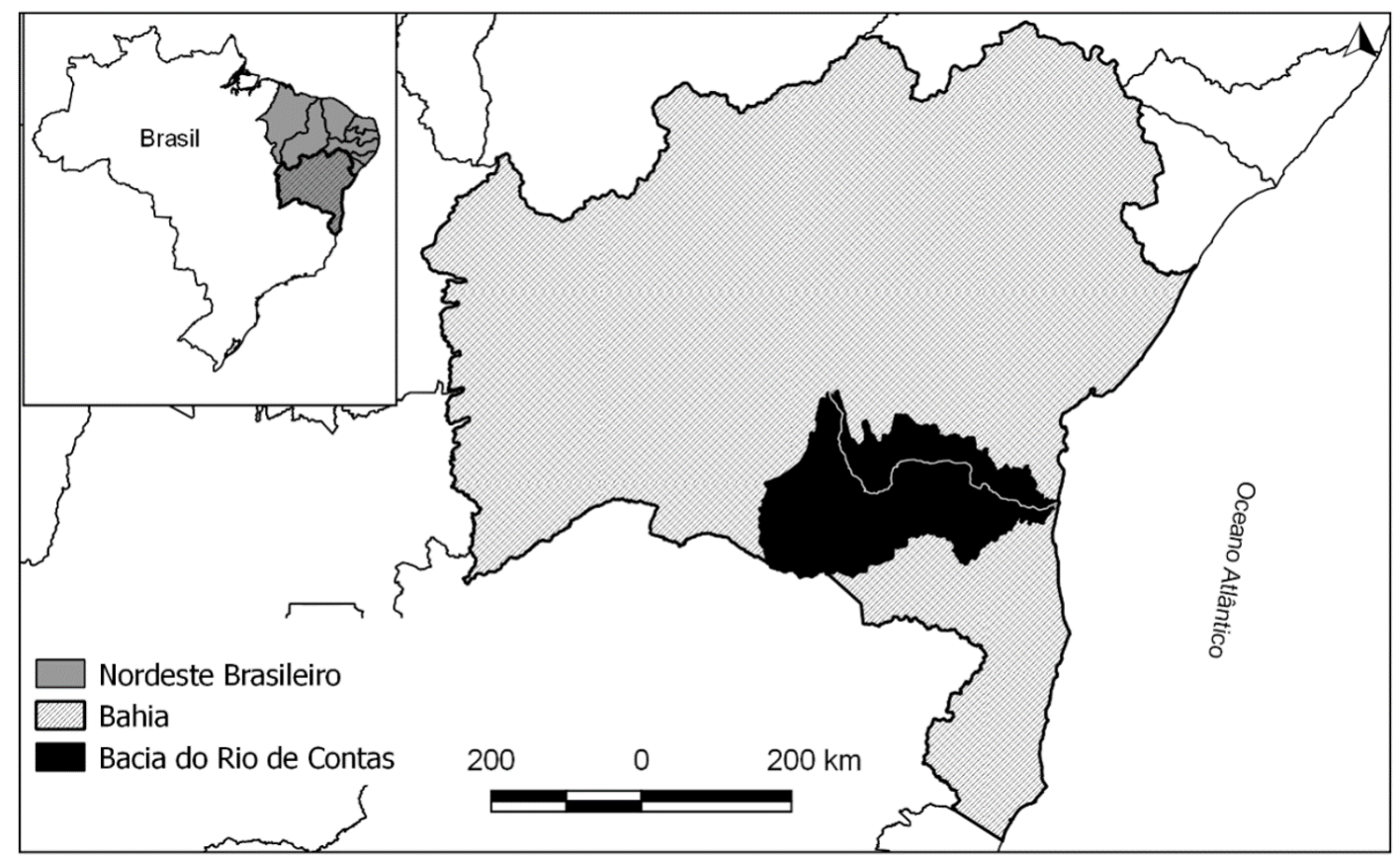

Fonte: Elaboração própria a partir de informações do Comitê da bacia hidrográfica do Rio das Contas (2013).

A bacia hidrográfica do Rio das Contas está localizada na região Centro-Sul da Bahia. Essa bacia possui área total de aproximadamente $55.482 \mathrm{~km}^{2}$, o que equivale a $10,2 \%$ do território do estado. É a maior bacia hidrográfica totalmente contida no estado da Bahia, engloba 92 municípios (Comitê da bacia hidrográfica do Rio das Contas, 2013) e está inserida na região hidrográfica do Atlântico Leste. A população da bacia é de 2.148 .031 habitantes, $15,3 \%$ da população do estado baiano. Desse 
total, 752.427 habitantes, o que corresponde a 35\%, vivem no meio rural (PNUD, 2013).

A economia dos municípios da bacia é bastante dependente da agricultura e da pecuária extensiva. Trata-se de uma região com baixo nível de desenvolvimento humano. Conforme dados do (PNUD, 2013), o Índice de Desenvolvimento Humano Municipal (IDH-M) regional médio é de 0,585, valor classificado como baixo e inferior ao valor médio do estado da Bahia, que é de 0,631. Entre as três dimensões do IDH-M, a educação é a que apresenta o menor valor para todos os municípios da bacia. Esse é um fator de preocupação e que será considerado neste estudo, tanto na composição do índice de vulnerabilidade quanto na análise da adaptação.

A bacia estende-se no sentido Leste-Oeste por cerca de $700 \mathrm{~km}$, com desnível total de 615 m, compreendendo três diferentes biomas: i) Cerrado na Chapada Diamantina ("Alto Contas"); ii) Caatinga ("Médio Contas"); e iii) Mata Atlântica ("Baixo Contas") (Paula et al., 2010). Nesse sentido, possui elevados níveis de variabilidade espacial e temporal das condições climáticas. Ademais, de acordo com (Carlos et al., 2019), a região

(...) compreende o clima tropical chuvoso de floresta, caracterizado pela ausência de estação seca, pluviosidade média mensal superior a $60 \mathrm{~mm}$ e anual superior a $1.500 \mathrm{~mm}$, temperatura do mês mais frio acima de $18^{\circ} \mathrm{C}$ e verões longos e quentes com temperatura do mês mais quente superior a $22^{\circ} \mathrm{C}$; o clima seco (típico de caatinga), cuja principal característica é a ausência de excedente hídrico, é acompanhado pela predominância de chuvas de verão e período seco bem definido de inverno e temperatura média superior a $18^{\circ} \mathrm{C}$; e o clima tropical de altitude, com predominância de chuvas de verão e seca de inverno, temperatura do mês mais frio superior a $18^{\circ} \mathrm{C}$, temperatura do mês mais quente superior a $22^{\circ} \mathrm{C}$ e altitude superior a 1200 m (Carlos, Cunha e Pires, 2019, p. 462).

Pode-se afirmar, em linhas gerais, que se trata de uma região seca. Seguindo as distintas definições de seca apresentadas Mishra e Singh (2010), é possivel identificar, inicialmente, que a bacia enfrenta a "seca hidrológica", com oferta inadequada de recursos hídricos superficiais. Segundo Chiapetti (2017, p. 9), “o rio das Contas (...) não tem um grande volume de água, devido aos rigores do clima semiárido, com ausência de chuva em grande parte do ano e com perda de água por evaporação”. A autora ressalta que esse fato é agravado devido à existência de uma barragem, na cidade de Jequié, que foi construída “(...) para controle das enchentes, abastecimento d'água, irrigação agrícola e geração de energia elétrica” (Chiapetti, 2017, p. 9). Ademais, conforme informações da ANA (2016), a região está enfrentando grande redução de chuvas, o que caracteriza a "seca meteorológica". De fato, dados disponibilizados por Xavier et al. (2016) indicam que a precipitação média anual dos municípios estudados nesta pesquisa se reduziu à taxa de aproximadamente $3 \%$ ao ano no período 
de 1985 a 2015. Essas informações permitem concluir que a bacia do Rio das Contas está também exposta ao que Mishra e Singh (2010) caracterizam como "seca socioeconômica", já que a disponibilidade de recursos hídricos dificulta o atendimento das demandas da população local.

Em termos de mudanças climáticas, cenários futuros projetados pelo IPCC (2013) indicam que a região da bacia do Rio das Contas poderá passar por grandes alterações de suas condições de temperatura e precipitação anuais. Por exemplo, para o período de curto-médio prazo (2016-2035), são esperadas reduções médias anuais da precipitação que podem variar entre 4,8 mm (cenário menos pessimista) e 12,8 mm (cenário mais pessimista); em termos de temperatura, são projetados aumentos médios anuais entre 0,58 e $0,67^{\circ} \mathrm{C}$. Já no longo-prazo (2046-2065), a chuva pode se reduzir entre 9,8 e $19,4 \mathrm{~mm}$ anuais e a temperatura pode aumentar entre 1,39 e $1,66^{\circ} \mathrm{C}$. $^{1}$ Além disso, os dados históricos publicados por Xavier et al. (2016) indicam que a região está passando por um processo de "aquecimento", o qual é a principal manifestação das mudanças do clima. Entre 1985 e 2015, a temperatura média anual aumentou $0,11 \%$ ao ano, passando de $24,4^{\circ} \mathrm{C}$ para $25,7^{\circ} \mathrm{C}$ (elevação de $1,3^{\circ} \mathrm{C}$ ).

\section{Revisão de literatura}

A literatura econômica sobre vulnerabilidade às (ou impactos das) mudanças climáticas e estratégias de adaptação no setor agrícola é vasta e diversa. Desde aquele que ficou conhecido como trabalho seminal na área, o artigo de Mendelsohn et al. (1994), e os diversos relatórios do IPCC, milhares de pesquisas estão sendo feitas por meio das mais diversas metodologias, unidades de análise e regiões de estudo. Podese afirmar que duas conclusões são comuns a todas os estudos. A primeira é que analisar vulnerabilidade ou adaptação não é um processo simples, já que a vulnerabilidade pode ser vista como resultado da capacidade adaptativa; porém, ao mesmo tempo, pode influenciar também na capacidade de se adaptar. Regiões, setores e indivíduos vulneráveis podem não ter recursos para se adaptar, da mesma forma que adaptação ineficiente ou insuficiente pode aumentar ainda mais a vulnerabilidade ambiental (Obermaier e Rosa, 2013). A segunda é bastante simples e até mesmo óbvia: as mudanças climáticas levarão a reduções de produtividade agrícola e criarão riscos globais e desiguais. Diante dessas conclusões, a presente seção não tem como objetivo fazer uma longa revisão de literatura sobre o tema, o que seria inviável e ineficaz. Aqui serão discutidos apenas alguns trabalhos que analisaram o Brasil e apresentaram resultados relevantes para a discussão deste estudo, sobretudo aqueles cujo foco é regional.

Inicialmente, para contextualizar o debate, Nelson et al. (2014) estimaram que o Brasil pode sofrer perdas de produtividade agrícola de até $25 \%$ até 2050 . Segundo

\footnotetext{
${ }^{1}$ Esses valores foram obtidos a partir de dois cenários futuros propostos pelo IPCC (2013) especificamente para os municípios da bacia do Rio das Contas. Esses cenários são chamados de Representative Concentration Pathways (RCP4.5 e RCP8.5).
} 
esses autores, os efeitos negativos sobre a produtividade levam a preços mais altos e, por conseguinte, à expansão de áreas e a mais desmatamento, realocação de recursos através do comércio internacional e redução de consumo, principalmente nas áreas mais pobres. De modo complementar, Assunção e Chein (2016) "sugerem que, sob os atuais padrões tecnológicos, o aquecimento global deverá reduzir a produção agrícola por hectare no Brasil em 18\%, com efeitos nos municípios variando de -40 a + 15\%". Se, por um lado, Assunção e Chein (2016) apresentam resultados desagregados a nível municipal, avançando em termos da possibilidade de planejamento regional ou local, por outro lado desconsideram estratégias de adaptação. Nelson et al. (2014) igualmente pressupõem um cenário no qual as práticas agrícolas permanecem inalteradas à medida que o clima se transforma.

Considerando a possibilidade de adaptação, Pires e Cunha (2014); Cunha et al. (2015); Abrahão e Costa (2018) avaliaram os impactos das mudanças climáticas na agricultura brasileira. Independentemente do tipo de estratégia adaptativa considerada (melhoramento genético no primeiro e no quarto artigo, irrigação no segundo e sistemas agroflorestais no terceiro), os três artigos comungam a conclusão de que a vulnerabilidade da agricultura tende a diminuir quando os agricultores se adaptam. Em alguns casos, como no artigo de Abrahão e Costa (2018), os resultados indicam que o melhoramento genético permitiu que a soja pudesse ser plantada em todas as regiões do Brasil ao longo do século XX, chegando a regiões com condições climáticas bastante diversas daquelas que a cultura tolerava na época de sua inserção no país.

Dado que a vulnerabilidade e a adaptação são processos específicos do lugar e do contexto, seus resultados podem ser alterados por meio de ações individuais. Para muitas regiões e setores, ambas as variáveis são fortemente influenciadas pelo comportamento e pela cultura dos agentes envolvidos, bem como por sua localização e seus meios de sobrevivência (Carlos et al., 2019). Essa premissa está implícita nos estudos de (Lindoso et al., 2014; Carlos et al., 2019). Todos esses autores consideraram como unidade de análise o agricultor nordestino e avaliaram como ele toma suas decisões no contexto de mudanças climáticas. Lindoso et al. (2014) encontraram que a baixa precipitação na região semiárida do Ceará foi responsável pelos elevados índices de vulnerabilidade dos agricultores, impulsionada por fatores institucionais e socioeconômicos. Gori Maia et al. (2018) demonstram que, com o aumento na temperatura média regional, os agricultores familiares do sertão nordestino migrarão para as atividades pecuárias, consideradas por eles como mais resistentes e com menor custo de oportunidade. Carlos et al. (2019) identificaram que a percepção das mudanças climáticas somente causa influência na decisão de adaptação se o agricultor acredita nos potenciais impactos negativos do fenômeno.

De modo geral, não apenas os poucos trabalhos destacados aqui, mas a literatura como um todo, chama a atenção para o papel fundamental da adaptação eficiente como forma de diminuir a vulnerabilidade dos agricultores, já que a mudança climática exacerba outras ameaças aos sistemas sociais e naturais (IPCC, 2014). Por isso, 
espera-se que a necessidade de adaptação, juntamente com os desafios correlacionados, aumente com a mudança climática. Felizmente, existem opções de adaptação em todos os setores e em todas as regiões, cabendo aos agentes econômicos que as empreguem da maneira mais eficiente no contexto da vulnerabilidade local.

\section{Metodologia}

\subsection{Análise da vulnerabilidade}

O IPCC (2001) definiu vulnerabilidade às mudanças climáticas como sendo

(...) o grau de suscetibilidade de um sistema aos efeitos adversos da mudança climática, ou sua incapacidade de administrar esses efeitos, incluindo variabilidade climática ou extremos. Vulnerabilidade é função do caráter, da dimensão e da taxa de variação climática aos quais um sistema é exposto, sua sensibilidade e capacidade de adaptação (IPCC, 2001).

Quando se pretende analisar a vulnerabilidade de um sistema socioeconômico, no qual questões socioeconômicas da comunidade local influenciam-se mutuamente, deve-se verificar o quanto ele está suscetível às alterações dos fenômenos naturais e ponderar a significância de potenciais prejuízos daí decorrentes (Cutter e Finch, 2008). A vulnerabilidade é, portanto, função das características de comunidade e das possíveis mudanças em seus recursos naturais. Por essa razão, ao medir o grau de vulnerabilidade, não se pode deixar de considerar os fatores relativos à sensibilidade, exposição e capacidade adaptativa. Dependendo de como se comportam tais elementos, um sistema pode ser classificado como mais vulnerável ou menos vulnerável às mudanças climáticas.

O conceito de sensibilidade surge da interação entre os eventos climáticos e os sistemas socioeconômicos, de acordo com suas características internas, e reflete como ele reage a essas perturbações. A exposição, por sua vez, está relacionada à "presença de pessoas, meios de subsistência, espécies ou ecossistemas, funções ambientais, serviços e recursos, infraestrutura ou ativos econômicos, sociais ou culturais em lugares e cenários que poderiam ser afetados negativamente” (IPCC, 2014). Já a capacidade adaptativa é definida como "a capacidade de sistemas, instituições, seres humanos e outros organismos se ajustarem a possiveis danos, aproveitarem oportunidades ou responderem a consequências" (IPCC, 2014).

Portanto, o presente artigo investiga a vulnerabilidade do sistema socioeconômico formado pelos agricultores da bacia hidrográfica do Rio das Contas. Em outras palavras, foi analisado o quanto as condições econômicas e sociais dos referidos agricultores e de sua região têm sido transformadas pelas mudanças históricas das condições climáticas (ou seja, sua exposição às variações de temperatura e precipitação, 
incluindo eventos extremos) e como tais alterações podem ser agravadas ou compensadas pelos seus atributos de sensibilidade e capacidade adaptativa.

Para isso, foi calculado o Índice de Vulnerabilidade $(V)$ de cada agricultor seguindo a proposição metodológica de Lindoso et al. (2014):

$$
V=\frac{S+E+(1-C A)}{3}
$$

em que $S$ se refere ao subíndice de Sensibilidade, $E$ se refere ao de Exposição e $C A$ se refere ao de Capacidade Adaptativa. Quanto mais próximo de 1, maior será a vulnerabilidade. O resultado do subíndice de Capacidade Adaptativa é subtraído de 1 devido à sua relação inversa com a vulnerabilidade. Por fim, ressalta-se que cada dimensão tem o mesmo peso na construção final do conceito de vulnerabilidade (denominador é igual a 3), pois a literatura considera que sensibilidade, exposição e capacidade adaptativa constituem-se como elementos igualmente importantes para explicar o efeito das mudanças climáticas sobre os agentes econômicos (Hahn et al., 2009; Lindoso et al., 2014).

Para obter o valor de cada subíndice que forma o conceito de vulnerabilidade, a metodologia aqui empregada foi baseada em Hahn et al. (2009). Os subíndices, por sua vez, foram compostos por distintas variáveis, definidas com base em Lindoso et al. (2014). Em linhas gerais, as variáveis se referem à existência de renda de atividades não agrícolas, ao número de dependentes na propriedade, à produção de sequeiro ou irrigada, ao seguro de exploração agrícola, ao acesso a recursos hídricos no estabelecimento (Sensibilidade); aos índices históricos representativos de seca, à inundação e ao aumento de temperatura (Exposição); e à escolaridade, à propriedade da terra, ao acesso à assistência técnica e ao crédito agropecuário, à participação em associações de classe ou projetos públicos de irrigação (Capacidade Adaptativa). A descrição completa dessas variáveis é apresentada na Tabela A1, do Anexo.

Como as variáveis são medidas em escalas diferentes, Hahn et al. (2009) sugerem, inicialmente, padronizá-las para que todas variem entre 0 e 1. A Equação (2) usada para essa conversão foi:

$$
X_{k i}=\frac{k_{i}-k_{i \min }}{k_{\text {imax }}-k_{\text {imin }}}
$$

em que $k_{i}$ é a variável original do produtor $i$, e $k_{i m i n}$ e $k_{i m a x}$ são os valores mínimo e máximo, respectivamente, para cada variável determinada. Esses valores mínimos e máximos foram usados para transformar esse indicador em um valor padronizado para que pudesse ser integrado a cada subíndice $I_{j}$.

Após a padronização, procede-se o cálculo do valor de cada subíndice, de acordo com a Equação (3): 


$$
I_{j}=\frac{\sum_{k=1}^{n} f_{k} X_{k i}}{\sum_{k=1}^{n} f_{k}}
$$

em que $j$ representou o subíndice a ser criado $(j=1$ quando o subíndice foi relativo à sensibilidade, $j=2$ quando se tratou do subíndice de exposição e $j=3$ quando foi referente ao subindice de capacidade adaptativa); $X_{k i}$ representou o valor padronizado de cada uma das $k$ variáveis que compuseram o respectivo subíndice para cada agricultor $i$; e $f_{k}$ foi o peso atribuído à cada variável. A escolha dessa metodologia permite demonstrar como diferentes variáveis socioeconômicas e demográficas impactam os componentes da vulnerabilidade.

Para a atribuição de pesos a cada uma das variáveis que compõem os subíndices, o presente estudo utilizou o modelo Ricardiano (ou Hedônico). O método foi utilizado para estimar a relação de longo prazo entre os valores das terras dos agricultores e as variáveis exógenas que refletem às dimensões de vulnerabilidade consideradas neste estudo (clima e condições socioeconômicas). Essa metodologia foi originalmente proposta por Mendelsohn et al. (1994) para analisar o impacto do aquecimento global sobre a agricultura dos Estados Unidos, o que pode ser interpretado como maneira alternativa de analisar a vulnerabilidade do setor agrícola às mudanças climáticas. Assim, buscou-se encontrar pesos que refletissem a contribuição dessas variáveis para os níveis de vulnerabilidade, através de seu impacto no valor das terras agrícolas. A versão do modelo Ricardiano adaptada para esta pesquisa foi baseada no trabalho de Van Passel et al. (2017). ${ }^{2}$ Esses autores utilizaram o modelo para estimar como o valor da terra pode ser impactado por diferentes categorias de variáveis climáticas e socieconômicas, as quais guardam relação direta com as noções de sensibilidade, exposição e capacidade adaptativa. Após a estimação do modelo Ricardiano, o módulo dos coeficientes estimados representou o peso de cada variável no cálculo dos subíndices, conforme a Equação (3) proposta por Hahn et al. (2009).

\subsection{Análise da adaptação}

A capacidade adaptativa é considerada um componente que auxilia positivamente o sistema socioeconômico na redução de sua vulnerabilidade (Engle, 2011). Apresentar elevada capacidade adaptativa significa que o sistema tem a possibilidade de realizar ajustamentos que efetivamente minimizem os possiveis impactos das mudanças climáticas. A adaptação, por sua vez, pode ser compreendida como a materialização da capacidade adaptativa. É a aplicação de meios para se reduzir a vulnerabilidade a partir do potencial que um sistema possui. Consiste no ato de se realizar mudanças visando lidar com problemas relacionados à sensibilidade ou exposição de uma localidade como reflexo da sua capacidade adaptativa. É possível distinguir estratégias de adaptação de acordo com o tamanho da mudança requerida para se alcançar um objetivo específico. Pode ser que o foco seja tecnológico ou institucional, pouco ou

\footnotetext{
${ }^{2}$ Detalhes sobre o modelo de Van Passel et al. (2017) estão disponíveis no Anexo deste artigo.
} 
muito difundido, espontâneo ou planejado, de maneira antecipada ou reativa (Smit e Wandel, 2006).

A decisão de adaptação dos agricultores da bacia hidrográfica do Rio das Contas foi analisada por meio da questão: "Nos últimos anos você tem alterado a forma de conduzir sua propriedade (mudança de técnicas produtivas, alteração de datas de plantio, uso sementes geneticamente melhoradas etc.) de modo a proteger-se de alterações climáticas?”. No questionário utilizado por Carlos et al. (2020), cujos dados foram disponibilizados para esta pesquisa, os agricultores poderiam responder "sim" ou "não" a essa questão, originando, assim, uma variável binária. Como sequência dessa questão, era solicitado aos agricultores que responderam "sim", identificar qual foi a medida adaptativa implementada.

Nesse contexto, a decisão de adaptação às alterações climáticas foi analisada por meio de um modelo de escolha binária, que pressupõe um produtor representativo e avesso ao risco que decide adaptar-se, caso obtenha benefícios líquidos. Considera-se $A_{i}^{*}$ uma variável latente que captura os benefícios esperados a partir da adaptação:

$$
A_{i}^{*}=X_{i} \alpha+\varepsilon_{i}
$$

em que a decisão observada do produtor é $A_{i}=1$ se a resposta em relação à adaptação foi positiva $A_{i}^{*}>0$ e $A_{i}=0$ caso contrário; $X$ representa um vetor de variáveis exógenas que influenciam a decisão.

O modelo Probit pode ser utilizado para calcular a probabilidade de $p_{i}$, dada função de distribuição normal padrão acumulada:

$$
P_{i}=\int_{-\infty}^{\eta_{i}} \frac{1}{\sqrt{2 \pi}} \exp \left(-1 \frac{1}{2} u^{2}\right) d u
$$

A Equação (5) pode ser reescrita como:

$$
P_{i}=\Phi\left(\eta_{i}\right)
$$

em que $\Phi($.$) representa a função de distribuição acumulada da distribuição normal$ padrão. A transformação Probit é dada pelo inverso da função de distribuição normal padrão acumulada:

$$
\begin{gathered}
\eta_{i}=\Phi^{-1}\left(p_{i}\right)=\operatorname{probit}\left(p_{i}\right) \\
\Phi^{-1}\left(p_{i}\right)=\sum_{k=0}^{K} \beta_{k} X_{i k}
\end{gathered}
$$


O modelo Probit pode ser escrito como:

$$
P_{i}=\Phi\left(\sum_{k=0}^{K} \beta_{k} X_{i k}\right)
$$

A função Probit tem distribuição simétrica ao redor de $p=0,5$, em que $\operatorname{probit}(p)=0$. À medida que $p$ se aproxima de $1, \operatorname{probit}(p)$ tende para $+\infty$ tende para $-\infty$ quando $\mathrm{p}$ se aproxima de 0 .

Para a correta definição do vetor $X$, neste estudo consideraram-se as proposições de Yohe e Tol (2002). De acordo com esses autores, há oito determinantes para a adoção de estratégias adaptativas: (1) opções tecnológicas para adaptação; (2) disponibilidade de recursos; (3) estrutura das instituições e do processo de tomada de decisão; (4) estoque de capital humano; (5) estoque de capital social; (6) acesso a processos de redução de riscos; (7) gerenciamento de informação e credibilidade dos tomadores de decisão; e (8) exposição e percepção do público sobre fonte de estresse climático. De modo geral, o desenvolvimento desses autores explicita que a adaptação resulta da vulnerabilidade e que as variáveis de decisão são aquelas que caracterizam os conceitos de sensibilidade, exposição e capacidade adaptativa.

O primeiro desses oito determinantes foi representado, neste trabalho, pelas respostas dos agricultores que se adaptaram e a respeito de que técnicas foram utilizadas. Os demais fatores elencados por Yohe e Tol (2002) foram utilizados como variáveis explicativas para a estimação de um modelo de escolha binária (Probit), que teve como objetivo compreender a probabilidade de adaptação e seus determinantes. A descrição das variáveis utilizadas no modelo de adaptação, bem como o respectivo determinante da formulação de Yohe e Tol (2002) de cada variável estão demonstrados no Anexo, Tabela A2.

\subsection{Fonte dos dados}

Os dados utilizados para construção dos subíndices de sensibilidade e de capacidade adaptativa foram fornecidos por Carlos et al. (2020). Tais dados foram obtidos utilizando questionários semiestruturados, os quais foram aplicados no ano de 2014 (entre os meses de setembro e novembro) a 289 agricultores, em 26 municípios que compõem a bacia hidrográfica do Rio das Contas. As questões utilizadas encontramse no Anexo.

Dos 92 municípios que compõem a região da bacia, existem 145.647 estabelecimentos agrícolas (IBGE, 2006). Para determinar o tamanho da amostra, Carlos et al. (2020) utilizaram a seguinte equação:

$$
n=\frac{N p q\left(Z_{\alpha / 2}\right)^{2}}{p q\left(Z_{\alpha / 2}\right)^{2}+(N-1) E^{2}}
$$


em que $n$ é o tamanho da amostra; $N$ é o tamanho da população; $p$ é o percentual de produtores rurais da bacia do Rio das Contas; $q$ é a proporção complementar, ou seja, $(1-p) ; Z_{\alpha / 2}$ representa o grau de confiança desejado (nesse caso $95 \%$ ); e $E$ é o erro máximo da estimativa, a diferença máxima entre proporção amostral e a real proporção populacional.

Com o tamanho da amostra definido, os autores selecionaram os municípios que fizeram parte da amostra. Seguindo ainda a metodologia de Hartter (2009), foi criado um "buffer zone" que englobava municípios localizados a, no máximo, $50 \mathrm{~km}$ das margens do Rio das Contas, buscando incorporar diferentes zonas climáticas dentro da região da bacia.

Já os dados climáticos necessários para o cálculo do subíndice de exposição se referem a valores diários de precipitação e temperatura, no período de 1985 a 2014, disponibilizados pelo Terrestrial Hydrology Research Group (THRG). Por meio da metodologia proposta por Sheffield et al. (2006), partiu-se da unidade original dos dados, que é o grid. Utilizando um Sistema de Informação Geográfica - GIS, os pontos de grid foram unidos às coordenadas de latitude e longitude de cada agricultor. Posteriormente, foram construídas quatro variáveis, conforme definição de Alexander e Herold (2016): (i) número anual de dias em que a precipitação foi menor do que $1 \mathrm{~mm}$; (ii) número máximo de dias secos consecutivos (precipitação foi menor do que $1 \mathrm{~mm}$ ) - proxies de seca; ( $i i$ i) número anual de dias em que a precipitação foi maior do que $20 \mathrm{~mm}$ (proxy de enchente); porcentagem de dias em que a temperatura foi maior do que o $90^{\circ}$ percentil da distribuição diária local (proxy de aquecimento).

\section{Resultados e discussão}

Antes de apresentar e discutir os resultados obtidos neste estudo, foi realizado um panorama socioeconômicio e demográfico dos agricultores que participaram da pesquisa. ${ }^{3}$

Em termos demográficos, 83\% dos agricultores são do sexo masculino; $63 \%$ têm entre 40 e 69 anos, sendo a idade média 51 anos. A maior parte dos entrevistados é casada (80\%) e divide as atividades de produção ou administração do estabelecimento com o cônjuge. O número médio de residentes que são dependentes da renda gerada no estabelecimento é de aproximadamente cinco pessoas.

A análise do grau de escolaridade indica que $13 \%$ dos agricultores são analfabetos; $11 \%$ apenas sabem ler e escrever; $27 \%$ possuem nível fundamental incompleto; $10 \%$ possuem nível fundamental completo; $7 \%$ possuem nível médio incompleto; $21 \%$ possuem nivel médio completo; $4 \%$ possuem nivel superior incompleto e $7 \%$ possuem nivel superior completo. Quando perguntados sobre que tipo de formação agropecuária possuem, a maior parte dos agricultores (83\%) responderam "Aquela que aprendi

\footnotetext{
${ }^{3}$ Todas as informações apresentadas a seguir estão mais detalhadas em gráficos e tabelas disponíveis no Anexo.
} 
com meus pais e outros agricultores"; 14\% responderam "Cursos de Extensão agrícola ou similares"; $1 \%$ afirmou possuir "Formação profissional/técnica agrícola ou similares"; e os demais (2\%) concluíram "Estudos universitários específicos (Agronomia, Zootecnia ou Engenharia Florestal)”.

Dos 289 agricultores entrevistados, $86 \%$ são proprietários da terra onde produzem e 54\% informaram que sua única atividade econômica é a agricultura e, ou, a pecuária. As propriedades amostradas têm, em média, 34 hectares, sendo que a maior parcela delas (60\%) ocupa no máximo 10 hectares. Correspondendo a $37 \%$ do total, 108 agricultores produzem utilizando alguma técnica de irrigação, sendo que, desses, $24 \%$ participa de algum projeto público de irrigação. No que diz respeito à disponibilidade hídrica, 69\% possuem acesso a fontes de água no próprio estabelecimento.

A maioria dos participantes da pesquisa (70\%) afirmou não ter recebido assistência técnica no ano anterior à realização da pesquisa e somente $6 \%$ possuem seguro agrícola. Ao mesmo tempo, $73 \%$ responderam que não utilizam ou não têm acesso a nenhum tipo de crédito para o fomento de suas atividades. No que diz respeito à participação em associações ou sindicatos, 186 (64\%) afirmaram fazer parte. Por fim, $74 \%$ afirmaram estar dispostos a alterar futuramente suas práticas agrícolas para se adequarem aos cenários futuros de mudanças climáticas, ao passo que $52 \%$ já alteraram, no passado, suas técnicas de produção com vistas a reduzir perdas resultantes de alterações no clima, sobretudo da seca.

\subsection{Indicador de vulnerabilidade}

Na Tabela 1, são apresentados os valores médios da vulnerabilidade e seus atributos, sensibilidade, exposição e capacidade adaptativa. Os valores foram calculados para cada agricultor e, posteriormente, agregados a nível municipal. ${ }^{4}$ Parker et al. (2019) propõem analisar o índice de vulnerabilidade e seus componentes a partir de três categorias: "baixa" (quando o valor varia entre $0-0,3)$; "média" $(0,3-0,6)$; e "alta" $(0,6-1)$. Considerando a Tabela 1, quando a classificação era "alta”, os valores do índice de vulnerabilidade e dos subíndices de sensibilidade e exposição foram marcados pela cor vermelha; na classificação "média”, todos os valores foram marcados pela cor verde; e, na classificação "baixa", os valores do índice de vulnerabilidade e dos subíndices de sensibilidade e exposição receberam a cor azul, enquanto a capacidade adaptativa recebeu a cor vermelha.

Os resultados mostram que os valores médios para sensibilidade giram em torno de baixos (27\% dos municípios) a médios (69\%), sendo que apenas um município apresentou valor alto. Entre as variáveis que compõem esse subíndice, as mais relevantes foram a "falta de acesso a fonte de água no próprio estabelecimento" e "produção de sequeiro", ou seja, impediram que o valor médio fosse ainda menor. Esse resultado sinaliza que políticas públicas voltadas para facilitar a produção irrigada poderiam

\footnotetext{
${ }^{4}$ Os pesos das variáveis de componente da vulnerabilidade foram obtidos pelo modelo Hedônico, cujos resultados estão apresentados na Tabela A3 do Anexo.
} 
contribuir para a redução da sensibilidade dos agricultores.

Tabela 1. Valor médio os índices de sensibilidade, exposição e capacidade adaptativa e vulnerabilidade por município

\begin{tabular}{|c|c|c|c|c|}
\hline Município & Sensibilidade & Exposição & $\begin{array}{l}\text { Capacidade } \\
\text { Adaptativa }\end{array}$ & Vulnerabilidade \\
\hline Jaguaquara & 0,15 & 0,16 & 0,47 & 0,28 \\
\hline Jequié & 0,54 & 0,02 & 0,53 & 0,34 \\
\hline Jitaúna & 0,33 & 0,00 & 0,24 & 0,36 \\
\hline Maracás & 0,12 & 0,63 & 0,51 & 0,41 \\
\hline Ubatã & 0,35 & 0,06 & 0,12 & 0,43 \\
\hline Boa Nova & 0,35 & 0,34 & 0,39 & 0,44 \\
\hline Mirante & 0,35 & 0,34 & 0,39 & 0,44 \\
\hline Manoel Vitorino & 0,48 & 0,37 & 0,46 & 0,46 \\
\hline Brumado & 0,23 & 0,70 & 0,52 & 0,47 \\
\hline Ibirapitanga & 0,44 & 0,29 & 0,32 & 0,47 \\
\hline Dom Basílio & 0,15 & 0,76 & 0,47 & 0,48 \\
\hline Itacaré & 0,41 & 0,35 & 0,30 & 0,49 \\
\hline Ilhéus & 0,48 & 0,33 & 0,33 & 0,50 \\
\hline Caetanos & 0,45 & 0,39 & 0,33 & 0,50 \\
\hline Jussiape & 0,22 & 0,81 & 0,45 & 0,53 \\
\hline Ibicoara & 0,27 & 0,83 & 0,42 & 0,56 \\
\hline Caraíbas & 0,52 & 0,64 & 0,43 & 0,57 \\
\hline Piatã & 0,32 & 0,83 & 0,41 & 0,58 \\
\hline Barra da Estiva & 0,57 & 0,67 & 0,48 & 0,59 \\
\hline Tanhaçu & 0,31 & 0,82 & 0,34 & 0,60 \\
\hline Livramento de Nossa Senhora & 0,40 & 0,85 & 0,44 & 0,60 \\
\hline Anagé & 0,76 & 0,50 & 0,43 & 0,61 \\
\hline Rio de Contas & 0,22 & 0,98 & 0,37 & 0,61 \\
\hline Aracatú & 0,51 & 0,87 & 0,37 & 0,67 \\
\hline Abaíra & 0,37 & 1,00 & 0,31 & 0,69 \\
\hline Ituaçu & 0,46 & 0,94 & 0,26 & 0,72 \\
\hline Média regional & 0,38 & 0,56 & 0,39 & 0,51 \\
\hline
\end{tabular}

Fonte: Resultados da pesquisa.

Em geral, a região possui elevados níveis de exposição (54\% dos munícipios na categoria alta e $27 \%$ na média). Isso está diretamente relacionado à seca recorrente que a região enfrenta, conforme discutido na segunda seção deste artigo. Os dados utilizados na construção desse subíndice indicam que no período de 1985 a 2014 houve, em média, 238 dias secos por ano, ao passo que chuvas mais fortes (superiores a $20 \mathrm{~mm}$ /dia) ocorreram em cerca de seis dias por ano. Ademais, dados apresentados por Xavier et al. (2016) mostram que a diferença entre a média anual de precipitação no ano de realização da pesquisa (2014) e a média dos 30 anos anteriores foi negativa para todos os municípios estudados, principalmente para aqueles não localizados no 
litoral.

Ainda sobre a questão da exposição, vale destacar que Marengo (2010) fez um panorama sobre a seca no Nordeste brasileiro no período de 2010 a 2016 e demonstrou que esse foi um período bastante severo de falta de chuva, com todos os anos (exceto 2011) tendo níveis de precipitação abaixo da média histórica. A duração e a intensidade dessa seca impactaram a economia regional em mais de 1.100 municípios, gerando problemas sociais tanto nas áreas urbanas quanto nas rurais, entre as quais está a região da Bacia hidrográfica do Rio das Contas. O autor acrescenta que, mesmo sendo um fenômeno recorrente na região, o risco e a vulnerabilidade permanecem elevados, principalmente nas áreas rurais.

Esta pesquisa identificou apenas valores baixos ou médios para a capacidade adaptativa: $12 \%$ e $88 \%$ dos municípios, respectivamente. Considerando que essa dimensão da vulnerabilidade é justamente a que atua no sentido de a diminuir, muito ainda precisa ser aprimorado nesse aspecto. Caso nenhuma mudança ocorra no curto ou médio prazo, esse resultado reduz muito as chances de adaptação futura aos impactos das mudanças climáticas.

A partir dos três subíndices descritos anteriormente e seguindo a classificação Parker et al. (2019), pode-se afirmar que 69\% dos municípios se encontram na categoria de média vulnerabilidade, $27 \%$ possuem vulnerabilidade alta e apenas $4 \%$ apresentam baixa vulnerabilidade (Tabela 1 e Figura 2).

Figura 2. Vulnerabilidade dos Municípios Pesquisados

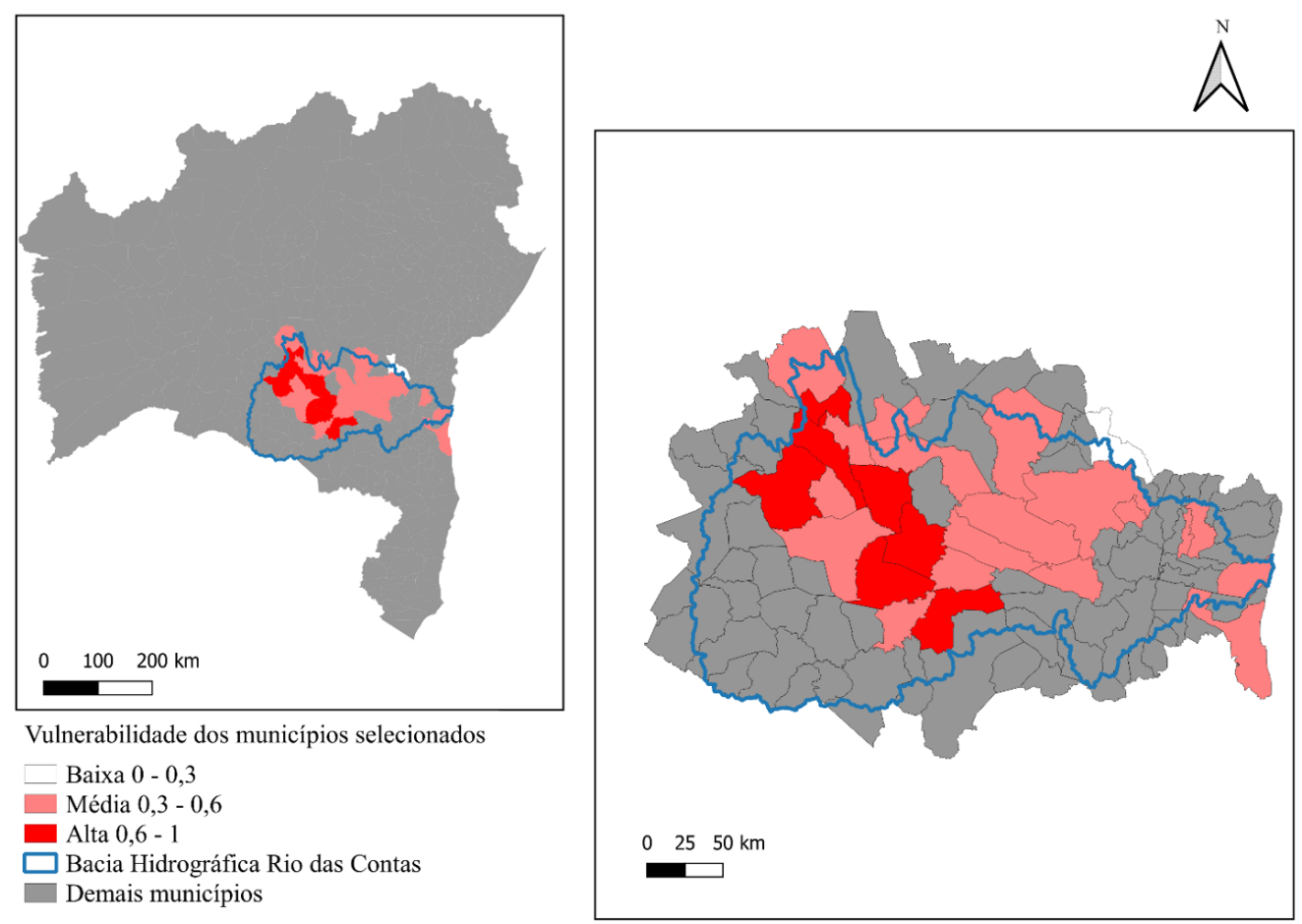

Fonte: Elaboração própria a partir dos resultados da pesquisa. 
A literatura aponta diversos caminhos que poderiam reduzir a vulnerabilidade, sendo que muitos deles passam, diretamente, pela melhoria da capacidade adaptativa. Algumas dessas pesquisas apontam que, quanto maior o nível de instrução e experiência, somado à formação específica para atuar na agropecuária, maior é a probabilidade de se implementarem novas práticas ou tecnologias de adaptação (Buainain, 2006; Below et al., 2012; Cunha et al., 2015). O elevado nível de educação pode promover melhor capacidade de análise de informação, de tomada de decisão, de flexibilidade para fazer alterações necessárias no processo e, assim, de ampliar o nível de resiliência dos agricultores. Esse efeito costuma ser reforçado se o agricultor é o proprietário da propriedade, por se tratar justamente do principal responsável pela produção e administração. Quanto maior seu nível de escolaridade e anos de experiência, maior a capacidade adaptativa (Below et al., 2012).

A assistência técnica e a extensão rural também podem promover a informação entre os produtores agrícolas e propiciar a adoção de técnicas mais apropriadas que poderiam diminuir a sua vulnerabilidade, como os sistemas de irrigação (Cunha et al., 2015), instruir sobre quais práticas são economicamente mais viáveis para cada contexto, além de capacitar os agricultores para a inovação (Buainain, 2006) e também aprimorar a sua capacidade de resposta. A ausência de assistência técnica frequente e de qualidade é considerada uma das principais fraquezas apontadas para as regiões menos desenvolvidas e mais vulneráveis (Painel Brasileiro de Mudanças Climáticas PBMC, 2013).

A possibilidade de os agricultores coletivamente se organizarem em associações ou sindicatos também pode propiciar o trânsito de informação e facilitar o acesso às políticas públicas, ao seguro agrícola, ao crédito, à aposentadoria, entre outros benefícios. É possível também que propiciem a criação de redes sociais baseadas em "solidariedade", o que, no caso de desastres, pode ser fator essencial para recuperação material e psicológica das pessoas atingidas (Jones e Boyd, 2011; Lindoso et al., 2014).

O acesso ao crédito influencia o nível de vulnerabilidade, porque aumenta a capacidade de financiamento para se desenvolverem e implementarem técnicas de adaptação. A ausência de mercados de crédito pode tornar proibitivo, principalmente para os agricultores de renda mais baixa, o investimento para adaptação climática (Hertel e Lobell, 2014).

Por fim, vale ressaltar que a análise dos resultados da vulnerabilidade e de seus subíndices em conjunto é fundamental para a eficácia das decisões tomadas pelos formuladores de política. E, para que as melhores políticas e estratégias sejam empregadas, deve-se ter como foco a escala microrregional (Lindoso et al., 2014).

\subsection{Processo de adaptação}

Os dados coletados na pesquisa indicam que 149 entre os 289 agricultores entrevistados, (52\%), realizaram algum tipo de adaptação na forma de conduzir a propri- 
edade como resposta à variabilidade do clima observada por eles ao longo do tempo. Verificou-se que o aumento do uso de irrigação foi a estratégia adaptativa mais utilizada por aqueles que alteraram sua forma de produzir, com 63 adeptos. Esse era um resultado esperado, já que parcela considerável dos agricultores têm suas propriedades localizadas próximas ao Rio das Contas. Em segundo lugar, com 32 produtores cada, encontram-se as estratégias de rotação e diversificação de culturas e de alteração nas datas de colheita. Outras possibilidades incluem alteração nas datas de plantio (30 agricultores), utilização do plantio direto na palha (19 agricultores), integração lavoura-pecuária-floresta ou sistemas agroflorestais (17 agricultores), utilização de plantas transgênicas ou geneticamente modificadas (13 agricultores), diminuição do plantio (13 agricultores), reflorestamento (9 agricultores) e preservação de nascentes ou matas ciliares (7 agricultores). Verifica-se que as estratégias mais utilizadas (exceto a irrigação) possuem a característica de serem de baixo custo de implementação. Algumas dessas medidas consistem em mudanças na estrutura de gastos recorrentes, em comportamentos, práticas ou estilos de vida relativamente fáceis de serem implementados (IPCC, 2014).

Feitas essas considerações sobre as estratégias adotadas, a pesquisa investigou, por meio de testes de média (Teste $t$ ), se houve diferença em termos do valor do Índice de Vulnerabilidade e seus compontes (Sensibilidade, Exposição e Capacidade Adaptativa) para agricultores que adotaram ou não adotaram medidas de adaptação (Tabela 2).

Tabela 2. Análise descritiva do Índice de Vulnerabilidade e seus compontes (Sensibilidade, Exposição e Capacidade Adaptativa) para agricultores que adotaram ou não adotaram medidas de adaptação

\begin{tabular}{|c|c|c|c|c|c|}
\hline \multirow{2}{*}{ Îndices } & \multicolumn{2}{|c|}{ Não adaptou ( $n=140)$} & \multicolumn{2}{|c|}{ Adaptou ( $n=149$ ) } & \multirow{2}{*}{ Teste $t$} \\
\hline & Média & $\begin{array}{l}\text { Erro- } \\
\text { padrão }\end{array}$ & Média & $\begin{array}{l}\text { Erro- } \\
\text { padrão }\end{array}$ & \\
\hline Vulnerabilidade & 0,54 & 0,0117 & 0,52 & 0,0113 & $1,13 N S$ \\
\hline Sensibilidade & 0,42 & 0,0236 & 0,36 & 0,0209 & $1,92^{*}$ \\
\hline Exposição & 0,57 & 0,0236 & 0,64 & 0,0233 & $-2,09^{* *}$ \\
\hline Capacidade Adaptativa & 0,36 & 0,0150 & 0,43 & 0,0135 & $-3,17^{* * *}$ \\
\hline
\end{tabular}

Nota: $\left.{ }^{* * *}\right),(* *)$ e $(*)$, respectivamente, indicam significância a 1\%, 5\% e 10\%; e $N S$ indica não significância; $n=289$ agricultores entrevistados.

Fonte: Resultados da pesquisa.

Observa-se que não há diferença estatisticamente significativa no Índice de Vulnerabilidade entre as duas categorias de agricultores. O subíndice de Sensibilidade indicou que os agricultores que não se adaptaram são mais sensiveis. Por sua vez, os subíndices de Exposição e Capacidade Adaptativa permitem afirmar, ainda que 
de modo preliminar, que as mudanças nos padrões de exposição, bem como a maior capacidade de investir em estratégias de adaptação são fatores condicionantes da mudança comportamental dos agricultores frente às alterações climáticas.

Visando aprofundar o conhecimento sobre o processo de adaptação dos agricultores, realizou-se a estimação do modelo Probit. Os coeficientes são apresentados na Tabela 3. O modelo estimado classificou corretamente $72,66 \%$ das observações, demonstrando bom ajuste. Quando a variável explicada (adaptação) adquire valor igual a 1, o modelo previu corretamente $72,48 \%$ das observações; quando igual a 0 , o modelo previu corretamente $72,86 \%$ das observações. A estatística Wald Chi2 obteve o valor de 62,94, com Prob > chi2 =0,0000 e Pseudo $R^{2}$ de 0,21, sendo significativa, o que leva à rejeição da hipótese nula de que todos os coeficientes da regressão são simultaneamente iguais a zero.

Tabela 3. Coeficientes das variáveis e efeitos marginais do modelo de escolha binária para análise de adaptação

\begin{tabular}{lcccc}
\hline \hline \multicolumn{1}{c}{ Variáveis } & Coeficientes & $\begin{array}{c}\text { Erro- } \\
\text { Padrão }\end{array}$ & Marginal & Padrão \\
\hline Parcela da renda oriunda de atividade agrícola & $0,0002 N S$ & 0,0027 & 0,0001 & 0,0010 \\
Possui renda de atividade não agrícola & $0,1222 N S$ & 0,2036 & 0,0485 & 0,0807 \\
Condição legal em relação a terra & $0,3367 N S$ & 0,2601 & 0,1337 & 0,1021 \\
Localização do município na Caatinga & $0,3630^{*}$ & 0,2071 & 0,1422 & 0,0797 \\
Acesso a crédito & $0,3172 N S$ & 0,1989 & 0,1241 & 0,0762 \\
Grau de escolaridade & $0,1178^{* * *}$ & 0,0449 & 0,0467 & 0,0178 \\
Número de residentes dependentes da renda & $0,0118 N S$ & 0,0112 & 0,0047 & 0,0044 \\
Participação em associação ou sindicato & $-0,1461 N S$ & 0,1864 & $-0,0578$ & 0,0734 \\
Participação em projeto de irrigação & $1,1417^{* * *}$ & 0,3816 & 0,3738 & 0,0854 \\
Possui formação agropecuária & $0,5983^{* * *}$ & 0,2090 & 0,2374 & 0,0826 \\
Recebimento de assistência técnica & $0,5741^{* * *}$ & 0,1928 & 0,2208 & 0,0707 \\
Subíndice de Exposição & $0,7853^{*}$ & 0,4331 & 0,3116 & 0,1717 \\
Percepção do agricultor a respeito das mudanças & $0,0229 N S$ & 0,1082 & 0,0091 & 0,0430 \\
climáticas e efeitos sobre as atividades agrícolas & & & & \\
\hline \hline
\end{tabular}

Notas: $\left({ }^{* *}\right)$ e (*) indicam, respectivamente, significância a 1\% e 10\% e $N S$ indica não significância; Wald Chi2 $=62,94$ (Prob > chi2=0,0000) e Pseudo $R^{2}=0,21 ; n=289$ agricultores entrevistados. Fonte: Resultados da pesquisa.

As variáveis "Grau de escolaridade", "Possui formação agropecuária", "Participação em algum projeto de irrigação", "Recebimento de assistência técnica”, "Localização" e o "Subíndice de Exposição" foram estatisticamente significativas. Todas as variáveis 
apresentaram os sinais esperados em relação a estimular a adaptação, com exceção de "Participação em alguma associação ou sindicato", mas essa variável não foi estatisticamente significativa.

Dentre os determinantes descritos por Yohe e Tol (2002), o segundo, o qual trata da disponibilidade de recursos, foi o que nesta pesquisa apresentou não significância para todas as suas variáveis. Considerando que essas variáveis relacionam a dependência dos agricultores a terra e à atividade, era de se esperar que a adaptação se efetivasse frente à possibilidade de perdas e prejuízos devido às mudanças climáticas. Mesmo que a realização da adaptação seja positivamente relacionada com essas variáveis, o resultado deste estudo indica que na bacia hidrográfica do Rio das Contas elas não estão entre seus principais motivadores. De acordo com Carlos et al. (2020), esse resultado pode estar sinalizando a existência de "valores simbólicos" não captados pela coleta dos dados. A vontade de permanecer na sua própria terra e preservar seu modo de vida pode exercer influência na tomada de decisão dos agricultores. Para essas pessoas, a atividade agrícola é mais do que apenas subsistência, representa também a sua cultura, sua história e sua maneira de viver em comunidade Carlos et al. (2020). Observando as respostas fornecidas pelos entrevistados, verifica-se que $64 \%$ residem nas propriedades, $86 \%$ têm a quem transferir a propriedade quando se aposentar e $48 \%$ afirmam que os filhos continuarão na atividade, contribuindo de alguma forma para a produção.

Outros dois fatores tendem a reforçar a possivel interferência de "valores simbólicos" neste estudo: a idade e o gênero dos agricultores. Em geral, agricultores mais jovens e do sexo feminino tendem a ser menos resistentes à adoção de novas técnicas de produção e de medidas adaptativas (Ngigi et al., 2017). No caso da presente pesquisa, a maior parte dos entrevistados é homem (83\%) e aproximadamente 54\% têm idade superior a 50 anos, sendo que, desses últimos, $20 \%$ têm 70 anos ou mais. É possivel que muitos desses agricultores, sobretudo os do sexo masculino, tenham aprendido o ofício com seus pais e, ou, avós, sendo, portanto, mais resistentes às mudanças requeridas pela adaptação.

O terceiro e o sexto determinantes se relacionam com estrutura das instituições, do processo de tomada de decisão e acesso a processos de redução de riscos. Como essas características variam para cada região, refletindo suas especificidades (Below et al., 2012), foram inseridas as variáveis "Localização" e "Acesso a crédito". A primeira foi estatisticamente significativa, apontando para o fato de que a adaptação é bastante dependente de fatores geográficos específicos (IPCC, 2007). O acesso a crédito afeta positivamente a adaptação, mas a variável pode ter sido não significativa nesta pesquisa, porque o crédito possivelmente está sendo usado para financiar a produção em si, em vez de processos de adaptação.

O quarto determinante é referente ao estoque de capital humano. Nesta pesquisa, buscou-se analisar esse aspecto através das variáveis "Grau de escolaridade" e "Número de residentes dependentes da renda gerada”, mas somente a primeira apresen- 
tou significância estatística. A literatura é enfática ao afirmar que o maior nível de educação está diretamente relacionado com assimilação de informações, tomada de decisão, ponderação entre as opções disponíveis etc. (Buainain, 2006; Below et al., 2012). Era de se esperar que, com um maior número de dependentes da renda gerada na propriedade, maior seria o estímulo a processos de adaptação, em virtude de que os prejuízos advindos das mudanças climáticas atingiriam mais pessoas, mas aparentemente esse não é um fator preponderante na região.

O estoque de capital social é analisado no quinto determinante através das variáveis "Participação em alguma associação ou sindicato" e "Participação em algum projeto de irrigação", das quais apenas a segunda foi estatisticamente significativa. A variável "Participação em algum projeto de irrigação" obteve o maior efeito marginal entre todas as variáveis, provavelmente pelo fato de os sistemas de irrigação constituírem-se como adaptação ao problema da seca e tornarem a propriedade menos dependente do clima (Buainain, 2006; Jones e Boyd, 2011; Lindoso et al., 2014; Cunha et al., 2015).

O sétimo determinante é formado pelas variáveis "Possui formação agropecuária" e "Recebimento de assistência técnica" e se trata do gerenciamento de informação e da credibilidade dos tomadores de decisão. Ambas as variáveis foram estatisticamente significativas. Já que são referentes à capacidade de interpretação e assimilação de informações, é de se esperar que elas tenham influência positiva no processo de adaptação. Esse resultado é similar ao da variável "Grau de escolaridade", ou seja, maior nivel de conhecimento e informação tem potencial de tornar os agricultores mais conscientes sobre os impactos das mudanças climáticas e a consequente necessidade de investir em adaptação (Below et al., 2012; Lindoso et al., 2014).

O último determinante trata da exposição e da percepção do público sobre as fontes de estresse climático, ao qual foram incorporados o "Subíndice de Exposição" e a "Percepção do agricultor a respeito das mudanças climáticas e efeitos sobre as atividades agrícolas". Ainda que ambas tenham sido positivamente relacionadas com a adaptação, apenas a primeira apresentou significância estatística. Mesmo que a percepção seja fator relevante para se implementar a adaptação, muitos fatores podem propiciar ou dificultar sua realização: características individuais do agricultor e de sua fazenda, redes sociais, organizações agrícolas, serviços de extensão rural, programas governamentais e políticas ambientais (Jackson, 2012).

Lemos e Kirchhoff (2016) apontam que nem sempre se verifica ligação direta entre informação e capacidade adaptativa. Algumas "dificuldades" podem obstruir a tomada de decisão e a efetiva concretização da adaptação, fruto muitas vezes da ineficiente interação entre os produtores do conhecimento e aqueles que vão utilizá-lo, refletindo relação de desconfiança e, ou, não cooperação. Isso promove problemas na disseminação e no processamento da própria informação climática, intensificada pela utilização de linguagem excessivamente técnica ou por ceticismo sobre as causas e os efeitos das mudanças do clima ou sobre a percepção que os usuários possuem da 
informação (Giulio et al., 2016).

Carlos et al. (2020) encontraram relação positiva entre percepção dos fenômenos climáticos e adaptação, mas também não foi significativa estatisticamente. Utilizando um modelo que mediava a percepção por meio de uma variável chamada de "Conhecimento/Crença na ocorrência das mudanças climáticas” e sua atuação sobre a adaptação, os autores concluíram que a adaptação só se origina da percepção se o agente acreditar que alterações no clima estão ocorrendo e possuir algum nível de conhecimento a respeito de suas possiveis causas e potenciais impactos sobre a atividade agrícola, além de saber discernir entre quais seriam as estratégias adaptativas mais adequadas para cada situação.

De acordo com Schuchardt et al. (2008), existem diversas possibilidades de adaptação e, em virtude disso, a configuração e a qualidade da ação dependem do acesso ao crédito e do conhecimento de práticas adaptativas, que aparentemente ainda é bastante insuficiente na região. Para Mitchell e Tanner (2006), a crença na ocorrência das mudanças climáticas e o conhecimento dessas práticas aumentam a eficiência e a efetividade do processo de adaptação em resposta a esses eventos.

A variável "Subíndice de Exposição" representa as mudanças na precipitação e na temperatura, as quais impactam o dia a dia do agricultor e, por essa razão, exercem influência de forma mais explícita do que a percepção. Nos municípios analisados nesta pesquisa, observou-se que o Índice de Exposição foi elevado. As oscilações nos padrões de precipitação, associadas aos aumentos de temperatura, modificam as necessidades de água para cada cultura e sua produtividade, resultando em efeitos desiguais para cada agricultor, o que torna a produção de sequeiro mais suscetível, já que é mais dependente da disponibilidade e regularidade das chuvas (Walthall et al., 2013). Mudanças na frequência, na intensidade e na quantidade de água em uma localidade tendem a aumentar as dificuldades de gestão de práticas e de sistemas de irrigação (Walthall et al., 2013). Ademais, a insegurança em relação à ocorrência de chuvas se configura como um dos principais entraves para o desenvolvimento das práticas agropecuárias e a insuficiência de mecanismos de armazenamento de água agrava os impactos sociais, especialmente na região Nordeste, acentuando a desigualdade social e piorando inclusive os níveis de subnutrição crônica (Marengo, 2010). As estratégias de adaptação às mudanças climáticas que visem ser bem sucedidas precisam levar em consideração, em horizonte temporal de longo prazo, as mudanças em níveis de precipitação e temperatura, por causa de seus impactos associados à produção de alimentos, à saúde e à biodiversidade (Cooper et al., 2008). Para isso, faz-se necessário o desenvolvimento de técnicas que aumentem a produtividade, mas que também reduzam a incerteza acerca dos resultados da produção devido à variabilidade climática (Cooper et al., 2008). Ao realizar a adaptação e a gestão dos recursos ambientais, promove-se maior estabilidade e possibilidade de recuperação das perdas de rendimentos das culturas.

Por fim, ressalta-se a importância de desenvolvimento de políticas públicas muni- 
cipais para aumentar a capacidade adaptativa dos agricultores, contribuindo assim para o seu efetivo investimento em estratégias de adaptação. Essa é uma realidade ainda distante na região. Segundo Vale Júnior et al. (2017) as dificuldades fiscais e as reduzidas condições de geração de receitas próprias dos municípios da bacia hidrográfica do Rio das Contas tornam quase impossível "a execução de políticas públicas que pudessem melhorar a qualidade de vida da população". Dessa forma, toda a região acaba ficando dependente de "programas sociais do governo federal, principalmente para custeio de educação, saúde, saneamento básico e investimentos em infraestrutura" (Vale Júnior et al., 2017).

\section{Considerações finais}

A partir dos resultados obtidos na pesquisa, pode-se concluir que o nível de vulnerabilidade dos agricultores da bacia do Rio das Contas é relativamente alto. Esse resultado pode ser explicado, principalmente, pelos elevados índices de exposição às mudaças climáticas aos quais a região está submetida e também pela baixa capacidade adaptativa. Constatou-se ainda que o grau de escolaridade, incluindo formação agropecuária específica, e o recebimento de assistência técnica, bem como a localização da propriedade e o grau de exposição às mudanças climáticas são importantes condicionantes da adaptação dos agricultores.

Portanto, esforços no sentido de aumentar a capacidade adaptativa dos agricultores deveriam se tornar cada vez mais o centro das políticas de desenvolvimento regional. Essas políticas deveriam se concentrar, entre outros fatores, na melhoria da qualidade educacional na região e na ampliação da oferta de assistência técnica e extensão rural. Níveis mais elevados de educação têm potencial de gerar maior conscientização dos efeitos negativos que as mudanças climáticas podem causar na agricultura e mais compreensão das causas e possíveis formas de elaborar soluções. Ademais, a adoção de medidas que visam lidar com as mudanças do clima pode ser ampliada a partir do incentivo oferecido por políticas que garantam mais informações práticas obtidas por meio da assistência técnica.

O presente estudo apresenta algumas limitações que devem ser ressaltadas. Incialmente, em termos dos dados disponíveis sobre sensibilidade e capacidade adaptativa, séries temporais mostrando a evolução das condições socioeconômicas dos agricultores possibilitariam uma análise dinâmica da vulnerabilidade e não apenas o panorama estático aqui evidenciado. O subíndice de Exposição, por sua vez, foi calculado a partir de dados municipais e médias anuais. Entretanto, dados de variáveis climáticas em resolução espacial e temporal mais refinada (a nível de estabelecimento agrícola e em observações diárias) possibilitariam o cálculo mais preciso da exposição dos agricultores entrevistados às mudanças climáticas. O debate sobre os pesos das variáveis que formam os subíndices ainda precisa avançar, dadas as limitações do modelo Hedônico aqui utilizado. Evidentemente, as limitações elencadas não invalidam esta pesquisa, já que resultados permitem debater padrões gerais de vulnerabilidade 
às mudanças climáticas em âmbito local.

Por fim, projeções climáticas futuras sintetizadas pelo IPCC (2014) sinalizam que os niveis de exposição às mudanças climáticas das regiões globais mais vulneráveis tendem a aumentar, amplificando as repercussões negativas dessas flutuações. Isso é válido para a região Nordeste do Brasil (Marengo, 2010) e, especificamente, para a bacia do Rio das Contas (Carlos et al., 2020). A partir desse diagnóstico, sugere-se o desenvolvimento de políticas públicas que tenham como objetivo combater a vulnerabilidade às mudanças climáticas, minimizando os prejuízos e facilitando o investimento em adaptação. Ademais, políticas devem fortalecer a capacidade adaptativa dos agentes e priorizar regiões que se encontram mais expostas aos efeitos negativos do clima. Cada dimensão da vulnerabilidade às mudanças climáticas precisa ser observada, atentando para as características próprias de cada localidade, seus pontos fortes e fracos, para que soluções com maior probabilidade de sucesso sejam empregadas.

\section{Referências}

Abrahão, G. M. e Costa, M. H. (2018). Evolution of rain and photoperiod limitations on the soybean growing season in Brazil: The rise (and possible fall) of double-cropping systems. Agricultural and Forest Meteorology, 256:32-45.

Alexander, L. e Herold, N. (2016). ClimPACT2 indices and software. WMO Commission for Climatology Expert Team on Sector-Specific Climate Indices.

ANA (2016). Rio de Contas está totalmente seco. Agência Nacional de Águas e Saneamento Básico.

Assunção, J. e Chein, F. (2016). Climate change and agricultural productivity in Brazil: future perspectives. Environment and Development Economics, 21(5):581602.

Below, T. B., Mutabazi, K. D., Kirschke, D., Franke, C., Sieber, S., Siebert, R., e Tscherning, K. (2012). Can farmers' adaptation to climate change be explained by socioeconomic household-level variables? Global Environmental Change, 22(1):223-235.

Buainain, A. M. (2006). Agricultura familiar, agroecologia e desenvolvimento sustentável: questões para debate. Embrapa Agrobiologia.

Carlos, S., da Cunha, D. A., Pires, M. V., e do Couto-Santos, F. R. (2020). Understanding farmers' perceptions and adaptation to climate change: The case of Rio das Contas basin, Brazil. GeoJournal, 85(3):805-821.

Carlos, S. d. M., Cunha, D. A. d., e Pires, M. V. (2019). Conhecimento sobre mudanças climáticas implica em adaptação? Análise de agricultores do Nordeste brasileiro. Revista de Economia e Sociologia Rural, 57(3):455-471. 
Cooper, P., Dimes, J., Rao, K., Shapiro, B., Shiferaw, B., e Twomlow, S. (2008). Coping better with current climatic variability in the rain-fed farming systems of subSaharan Africa: An essential first step in adapting to future climate change? Agriculture, ecosystems \& environment, 126(1-2):24-35.

Cunha, D. A., Coelho, A. B., e Féres, J. G. (2015). Irrigation as an adaptive strategy to climate change: an economic perspective on Brazilian agriculture. Environment and Development Economics, 20(1):57-79.

Cutter, S. L. e Finch, C. (2008). Temporal and spatial changes in social vulnerability to natural hazards. Proceedings of the National Academy of Sciences, 105(7):23012306.

Delazeri, L. M. M., da Cunha, D. A., e Couto-Santos, F. R. (2018). Climate change and urbanization: Evidence from the semi-arid region of Brazil. Revista Brasileira de Estudos Regionais e Urbanos, 12(2):129-154.

Engle, N. L. (2011). Adaptive capacity and its assessment. Global Environmental Change, 21(2):647-656.

Giulio, G., Di, M., Martins, A., Bedran, M., e Lemos, M. C. (2016). Adaptação climática: Fronteiras do conhecimento para pensar o contexto brasileiro. Estudos Avançados, 30(88):25-41.

Haddad, E. A., Porsse, A. A., e Pereda, P. C. (2013). Regional economic impacts of climate anomalies in Brazil. Revista Brasileira de Estudos Regionais e Urbanos, 7(2):19-33.

Hahn, M. B., Riederer, A. M., e Foster, S. O. (2009). The Livelihood Vulnerability Index: A pragmatic approach to assessing risks from climate variability and change-A case study in Mozambique. Global Environmental Change, 19(1):74-88.

Hartter, J. (2009). Attitudes of rural communities toward wetlands and forest fragments around Kibale National Park, Uganda. Human Dimensions of Wildlife, 14(6):433-447.

Hertel, T. W. e Lobell, D. B. (2014). Agricultural adaptation to climate change in rich and poor countries: Current modeling practice and potential for empirical contributions. Energy Economics, 46:562-575.

IBGE (2006). Censo Agropecuário: Brasil, Grandes Regiões e Unidades da Federação. Instituto Brasileiro de Geografia e Estatística.

Jackson, L. (2012). Vulnerability and adaptation to climate change in California agriculture. California Energy Commission.

Jones, L. e Boyd, E. (2011). Exploring social barriers to adaptation: insights from Western Nepal. Global environmental change, 21(4):1262-1274. 
Lindoso, D. P., Rocha, J. D., Debortoli, N., Parente, I. I., Eiró, F., Bursztyn, M., e Rodrigues-Filho, S. (2014). Integrated assessment of smallholder farming's vulnerability to drought in the Brazilian Semi-arid: a case study in Ceará. Climatic Change, 127(1):93-105.

Marengo, J. A. (2010). Vulnerabilidade, impactos e adaptação à mudança do clima no semi-árido do Brasil. Parcerias Estratégicas, 13(27):149-176.

Mendelsohn, R., Nordhaus, W. D., e Shaw, D. (1994). The impact of global warming on agriculture: a Ricardian analysis. The American economic review, Página 753-771.

Mishra, A. K. e Singh, V. P. (2010). A review of drought concepts. Journal of Hydrology, 391(1-2):202-216.

Nash, N., Capstick, S., Whitmarsh, L., Chaudhary, I., e Manandhar, R. (2019). Perceptions of local environmental issues and the relevance of climate change in Nepal's Terai: Perspectives from two communities. Frontiers in Sociology, 4:60.

Nelson, G. C., Valin, H., Sands, R. D., Havlikk, P., Ahammad, H., Deryng, D., Elliott, J., Fujimori, S., Hasegawa, T., Heyhoe, E., et al. (2014). Climate change effects on agriculture: Economic responses to biophysical shocks. Proceedings of the National Academy of Sciences, 111(9):3274-3279.

Ngigi, M. W., Mueller, U., e Birner, R. (2017). Gender differences in climate change adaptation strategies and participation in group-based approaches: an intrahousehold analysis from rural Kenya. Ecological Economics, 138:99-108.

Obermaier, M. e Rosa, L. P. (2013). Mudança climática e adaptação no Brasil: Uma análise crítica. Estudos Avançados, 27(78):155-176.

Parker, L., Bourgoin, C., Martinez-Valle, A., e Läderach, P. (2019). Vulnerability of the agricultural sector to climate change: The development of a pan-tropical Climate Risk Vulnerability Assessment to inform sub-national decision making. PloS one, 14(3):e0213641.

Pires, M. V. e Cunha, D. A. d. (2014). Climate change and adaptive strategies in brazil: the economic effects of genetic breeding. Revista de Economia e Sociologia Rural, 52(4):627-642.

PNUD (2013). Atlas do Desenvolvimento Humano no Brasil 2013. Programa das Nações Unidas para o Desenvolvimento.

Reyes-García, V., Fernández-Llamazares, Á., Guèze, M., Garcés, A., Mallo, M., VilaGómez, M., e Vilaseca, M. (2016). Local indicators of climate change: the potential contribution of local knowledge to climate research. Wiley Interdisciplinary Reviews: Climate Change, 7(1):109-124. 
Ripple, W. J., Wolf, C., Newsome, T. M., Galetti, M., Alamgir, M., Crist, E., Mahmoud, M. I., Laurance, W. F., e 15, . s. s. f. . c. (2017). World scientists' warning to humanity: a second notice. BioScience, 67(12):1026-1028.

Sheffield, J., Goteti, G., e Wood, E. F. (2006). Development of a 50-year high-resolution global dataset of meteorological forcings for land surface modeling. Journal of Climate, 19(13):3088-3111.

Smit, B. e Wandel, J. (2006). Adaptation, adaptive capacity and vulnerability. Global Environmental Change, 16(3):282-292.

Tol, R. S. (2018). The economic impacts of climate change. Review of Environmental Economics and Policy, 12(1):4-25.

Vale Júnior, J. S., de Alencar Gondim, I. M., dos Santos, J. B., e Neves, C. M. I. N. (2017). As políticas públicas para o desenvolvimento do território médio Rio das Contas: potencialidades e desafios. Revista Multidisciplinar e de Psicologia, 11(37):618-639.

Van Passel, S., Massetti, E., e Mendelsohn, R. (2017). A Ricardian analysis of the impact of climate change on European agriculture. Environmental and Resource Economics, 67(4):725-760.

Walthall, C. L., Anderson, C. J., Baumgard, L. H., Takle, E., Wright-Morton, L., et al. (2013). Climate change and agriculture in the United States: Effects and adaptation.

Xavier, A. C., King, C. W., e Scanlon, B. R. (2016). Daily gridded meteorological variables in brazil (1980-2013). International Journal of Climatology, 36(6):2644-2659.

Yohe, G. e Tol, R. S. (2002). Indicators for social and economic coping capacity-moving toward a working definition of adaptive capacity. Global Environmental Change, 12(1):25-40.

\section{Agradecimentos}

Esta pesquisa foi financiada pelo Conselho Nacional de Desenvolvimento Científico e Tecnológico - CNPq (Processos no 408382/2013-9; 306647/2015-0, 421791/20160 e 305807/2018-8); Fundação de Amparo à Pesquisa do Estado de Minas Gerais FAPEMIG (CSA-PPM-00022-14) e pela Coordenação de Aperfeiçoamento de Pessoal de Nivel Superior - CAPES (Código Financeiro 001). As fontes de financiamento não tiveram tal envolvimento no desenho do estudo; nem na coleta, análise e interpretação dos dados; e nem na redação do texto. 


\section{Anexos}

Ver Material Sumplementar no endereço eletrônico:

https://revistaaber.org.br/rberu/article/view/624.

@Ev Este artigo está licenciado com uma CC BY 4.0 license. 